\title{
TEKNIK EVAKUASI CEDERA KEPALA PASCA BENCANA KETEPATAN TEKNIK EVAKUASI PADA KORBAN CEDERA KEPALA DALAM MENGURANGI KEJADIAN CEDERA SEKUNDER
}

\author{
Noer Safita ${ }^{1}$, Anindya Atiqah Ristanti ${ }^{2}$, Eka Pramudian Rismayanti ${ }^{3}$, Hitaputra Agung Wardhana ${ }^{4}$ \\ 1,2,3,4 Universitas Muhammadiyah Surakarta \\ e-mail: safita_noer@gmail.com
}

\begin{abstract}
Evacuation is an effort to redeploy the victims from the affected area to a safer region to acquire the rescue. Nowadays the lack of a adequate transfer to evacuate disaster victims are the phenomenom which occur in social case spesifically the health workers who get high potency to increase the occurence of secondary injuries to victims. ratio of the results of health research at 2007 and 2013, point out the enhancement of prevalence of head injury from 7,5\% being 8,2\% and one of the hospital in Indonesia has held a data which made into a vocal point assert that head injury cases from year to year have increased. The aim of this literature review is to mitigate morbidity and mortality of head injury which go up every year and underpin the health workers to simplify in carry out evacuation to prevent secondary injuries. This literature review was conducted by seeking the electronic databases journal with engage corresponding keywords. The result of the study postulate the victim of injuries particularly post disaster need rapid and appropriate evacuation, assesment and management techniques to rescue suffers live. The treatment carried out when get a head injury is preserve the patients airway, oversee bleeding and preventing shock, immobilizing patient, avert complication and secondary injuries each circumstances which engage in abnormal and dangerous must be given resuscitation. The handling is done alluding to the necessity of ABCDE method by using the START method and mantain stabilization of the cervical technique using the log roll technique.
\end{abstract}

Keywords : Evacuation, head injury, secondary injury, disaster.

\begin{abstract}
Abstrak
Evakuasi adalah upaya untuk mempekerjakan kembali para korban dari daerah yang terkena dampak ke daerah yang lebih aman untuk mendapatkan pertolongan. Saat ini kurangnya transfer yang memadai untuk mengevakuasi korban bencana adalah fenomena yang terjadi dalam kasus sosial khususnya petugas kesehatan yang mendapatkan potensi tinggi untuk meningkatkan terjadinya cedera sekunder pada korban. rasio hasil penelitian kesehatan pada 2007 dan 2013, menunjukkan peningkatan prevalensi cedera kepala dari $7,5 \%$ menjadi $8,2 \%$ dan salah satu rumah sakit di Indonesia telah memegang data yang dibuat menjadi titik vokal menyatakan bahwa kasus cedera kepala dari tahun ke tahun mengalami peningkatan. Tujuan dari tinjauan literatur ini adalah untuk mengurangi morbiditas dan mortalitas cedera kepala yang meningkat setiap tahun dan mendukung petugas kesehatan untuk mempermudah dalam melakukan evakuasi untuk mencegah cedera sekunder. Tinjauan pustaka ini dilakukan dengan mencari jurnal basis data elektronik dengan menggunakan kata kunci yang sesuai. Hasil penelitian ini mendalilkan korban luka-luka terutama pasca bencana membutuhkan evakuasi yang cepat dan tepat, penilaian dan teknik manajemen untuk menyelamatkan hidup penderita. Perawatan yang dilakukan ketika mendapat cedera kepala adalah menjaga jalan napas pasien, mengawasi perdarahan dan mencegah syok, melumpuhkan pasien, mencegah komplikasi dan cedera sekunder setiap keadaan yang melibatkan abnormal dan berbahaya harus diberikan resusitasi. Penanganan dilakukan mengacu pada perlunya metode ABCDE dengan menggunakan metode START dan mantain stabilisasi teknik serviks menggunakan teknik log roll.
\end{abstract}

Kata kunci: Evakuasi, cedera kepala, cedera sekunder, bencana. 


\section{PENDAHULUAN}

Indonesia memiliki kondisi geografis, geologis, hidrologis, dan demografis yang memungkinkan terjadinya bencana, baik yang disebabkan oleh faktor alam, faktor nonalam maupun faktor manusia yang menyebabkan timbulnya cedera hingga korban jiwa.

Menurut Profil Kesehatan Indonesia tahun 2008 cedera merupakan penyebab kematian utama keempat $(6,5 \%)$ untuk semua umur setelah Stroke, TB, dan Hipertensi. Pada pola 10 penyakit penyebab kematian terbanyak di rumah sakit pada pasien rawat jalan cedera menempati urutan keenam, sedangkan pada pasien rawat inap menempati urutan keempat. ${ }^{1}$

Di Indonesia data epidemiologi tentang cedera kepala hingga saat ini belum tersedia,namun salah satu data rumah sakit di Indonesia menjelaskan bahwa kasus cedera kepala dari tahun ke tahun mengalami peningkatan. Data cedera kepala di Rumah Sakit Dr. Wahidin Sudirohusodo, Makasar pada tahun 2005 berjumlah 861 kasus, tahun 2006 berjumlah 817, dan tahun 2007 berjumlah 1.078 kasus. $^{2}$

Dari perbandingan hasil riset kesehatan dasar 2007 dan 2013, menunjukkan peningkatan prevalensi cedera kepala dari $7,5 \%$ menjadi $8,2 \%$ dan salah satu data rumah sakit di Indonesia menjelaskan bahwa kasus cedera kepala dari tahun ke tahun mengalami peningkatan. ${ }^{3}$

Penderita cedera kepala sering kali mengalami edema serebri yaitu akumulasi kelebihan cairan intraseluler atau ekstraseluler ruang otak atau perdarahan intrakranial yang mengakibatkan meningkatnya tekanan intrakranial ${ }^{4}$

Menurut Patomekanisme cedera kepala dapat terbagi menjadi cedera kepala primer dan sekunder. Cedera kepala primer merupakan cedera sebagai akibat dari ruda paksa atau kerusakan yang disebabkan trauma mekanis terhadap tulang kepala dan jaringan otak. Cedera sekunder merupakan cedera akibat dari proses patologik sebagai tahap lanjutan kerusakan otak primer. $^{5}$

Penyebab cedera sekunder bisa intrakranial bisa ekstrakranial atau sistemik. Penyebab intrakranial misalnya epidural, subdural, intraserebral hematoma, edema serebral, peningkatan ICP (Intracranial Pressure). Penyebab sistemik seperti hipoksemi, hiperkapni, hipotensi, anemi, hipertensi, hipoglikemi, hipertermi, sepsis. ${ }^{6}$

Jika di daerah dimana terjadi bencana tidak tersedia fasilitas kesehatan yang cukup untuk menampung dan merawat korban bencana massal (misalnya hanya tersedia satu Rumah Sakit tipe C/ tipe B), memindahkan korban ke sarana tersebut hanya akan menimbulkan hambatan bagi perawatan yang harus segera diberikan kepada korban dengan cedera serius. Lebih jauh, hal ini juga akan sangat mengganggu aktivitas Rumah Sakit tersebut dan membahayakan kondisi para penderita yang dirawat disana. Dengan ini harus dilakukan perawatan di lapangan yang adekuat bagi korban dapat lebih mentoleransi penundaan ini. Jika diperlukan dapat didirikan rumah sakit lapangan (Rumkitlap). Dalam mengoperasikan rumkitlap, diperlukan tenaga medis, paramedik, dan non medis. ${ }^{7}$

Fenomena yang terjadi pada saat ini adalah masih kurangnya transfer yang memadai untuk mengevakuasi korban bencana khususnya oleh tenaga kesehatan, seperti teknik mendorong/ menarik, membawa, memutar, menahan, dan mengangkat/ menurunkan pasien. Sehingga ketidaktepatan saat memindahkan pasien dapat berpotensi meningkatkan cedera berulang pada pasien. $^{8}$

Meskipun ada cara yang canggih dan penatalaksanaan yang mutakhir, prognosis cedera kepala traumatik masih tetap jelek. Derajat keparahan cedera primer merupakan faktor utama yang menentukan luaran, sedangkan cedera sekunder karena hipotensi, hipoksemia, hiperkarbia, 
hiperglikemi, dan hipoglikemia setelah cedera awal menyebabkan kerusakan lebih lanjut dari otak dan memperjelek luaran. ${ }^{6}$

Berdasarakan fenomena dan latar belakang diatas, maka penulis tertarik membahas mengenai "Teknik Evakuasi Cedera Kepala Pasca Bencana" untuk mengurangi angka morbiditas dan mortalitas cedera kepala yang meningkat tiap tahunnya dan mempermudah petugas kesehatan melakukan tindakan evakuasi serta mencegah terjadinya cedera sekunder atau cedera berulang.

\section{METODE}

Metode yang digunakan dalam penulisan artikel ini adalah literature review. Yaitu sebuah pencarian literatur baik internasional maupun nasional yang dilakukan dengan menggunakan database WHO, NCBI, Pubmed, Google Scholar dan ScienceDirect. Pada tahap awal pencarian artikel jurnal diperoleh 539 artikel dari tahun 2009 sampai 2019 menggunakan kata kunci "teknik evakuasi cedera kepala pasca bencana", "teknik evakuasi cedera kepala", head injury dan "evacuation techniques head injury".

\section{HASIL DAN PEMBAHASAN}

Evakuasi merupakan upaya untuk memindahkan korban dari lokasi yang tertimpa bencana ke wilayah yang lebih aman untuk mendapatkan pertolongan. ${ }^{9}$

Korban cedera khususnya pasca bencana memerlukan teknik evakuasi, penilaian dan pengelolaan yang cepat dan tepat untuk menyelamatkan jiwa penderita.

Evakuasi medik mempunyai ruang lingkup meliputi: evakuasi di lapangan (dari lokasi kejadian ke fasilitas kesehatan), evakuasi pelayanan (puskesmas ke rumah sakit, antar RS), evakuasi medik didalam RS (antar unit kerja terlibat). Teknik evakuasi medik untuk korban gawat darurat harus selalu disertai petugas medis menggunakan sarana transportasi yang memenuhi persyaratan pelayanan gawat darurat dengan memperhatikan tujuan evakuasi berdasarkan hasil triage (seleksi korban berdasarkan tingkat kegawatdaruratanya untuk memberikan prioritas pelayanan. ${ }^{10}$

Penanganan yang dilakukan saat terjadi cedera kepala adalah menjaga jalan nafas penderita, mengontrol pendarahan dan mencegah syok, imobilisasi penderita, mencegah terjadinya komplikasi dan cedera sekunder. Setiap keadaan yang tidak normal dan membahayakan harus segera diberikan tindakan resusitasi pada saat itu juga. Berkaitan dengan cedera kepala, maka sangat penting sekali dalam melakukan penanganan yang cepat dan tepat. $^{4}$

Pertimbangan paling penting dari cedera kepala adalah apakah otak telah mengalami cedera atau tidak dimana otak merupakan organ vital pengendali. ${ }^{11}$

Proses awal dikenal dengan Initial assessment (penilaian awal). Penilaian awal meliputi:

1. Persiapan

2. Triase

3. Primary survey (ABCDE)

4. Resusitasi

5. Tambahan terhadap primary survey dan resusitasi

6. Secondary survey

7. Tambahan terhadap secondary survey

8. Pemantauan dan re-evaluasi berkesinarnbungan

9. Transfer ke pusat rujukan yang lebih baik.

\section{Persiapan}

Dalam proses persiapan terdapat fase pra rumah sakit dan fase rumah sakit. Fase pra rumah sakit meliputi koordinasi yang baik antara dokter di rumah sakit dan petugas lapangan. Dan sebaiknya terdapat pemberitahuan terhadap rumah sakit sebelum penderita mulai diangkut dari tempat kejadian. Pengumpulan keterangan yang akan dibutuhkan di rumah sakit seperti waktu kejadian, sebab kejadian, mekanisme kejadian dan riwayat 
penderita. Sedangkan fase rumah sakit mengenai perencanaan sebelum penderita tiba, perlengkapan airway sudah dipersiapkan, dicoba dan diletakkan di tempat yang mudah dijangkau. Kemudian cairan kristaloid yang sudah dihangatkan, disiapkan dan diletakkan pada tempat yang mudah dijangkau. Pemberitahuan terhadap tenaga laboratorium dan radiologi apabila sewaktu-waktu dibutuhkan. Dan pemakaian alat-alat proteksi diri. ${ }^{12}$

Langkah-langkah dasar dalam melakukan pertolongan pertama gawat darurat ada 4, yaitu D-R-C-A-B. D (Dangerous) dengan mengamankan korban dari lingkungan yang membahayakan bagi keselamatan korban. R (Respon) memastikan korban dalam sadar atau tidak. C (Circulation), periksa sirkulasi nafas survei awal. A (Airways) dengan membuka jalan napas. B (Breathing) dengan memeriksa nafas. Evakuasi korban dapat dilakukan apabila DRCAB aman, patah tulang dan perdarahan sudah tertangan, perhatikan cedera leher/ cervical dan tulang punggung, rute aman bagi penolong dan korban. ${ }^{13}$

Sebagai tenaga medis dalam mengevakuasi korban perlu dilakukan berbagai teknik sebagai berikut:

\section{Pertolongan pertama}

Pertolongan pertama dilakukan oleh para sukarelawan, petugas Pemadam Kebakaran, Polisi, Tenaga dari unit khusus, Tim Medis Gawat Darurat dan Tenaga Perawat Gawat Darurat Terlatih. Pertolongan pertama dapat diberikan di lokasi seperti berikut: 1) Lokasi bencana, sebelum korban dipindahkan. 2) Tempat penampungan sementara. 3) Pada "tempat hijau"' dari pos medis lanjutan. 4) Dalam ambulans saat korban dipindahkan ke fasilitas kesehatan. ${ }^{7}$

Pertolongan pertama yang diberikan pada korban dapat berupa kontrol jalan napas, fungsi penapasan dan jantung, pengawasan posisi korban, kontrol pendarahan, imobilisasi fraktur, pembalutan dan usaha-usaha untuk membuat korban merasa lebih nyaman. Harus selalu diingat bahwa, bila korban masih berada di lokasi yang paling penting adalah memindahkan korban sesegera mungkin, membawa korban gawat darurat ke pos medis lanjutan atau pos komando sambil melakukan usaha pertolongan pertama utama, seperti mempertahankan jalan napas, dan kontrol pendarahan. Resusitasi kardiopulmoner tidak boleh dilakukan di lokasi kecelakaan pada bencana massal karena membutuhkan waktu dan tenaga. ${ }^{7}$

\section{Pos medis lanjutan}

Pos medis lanjutan dilakukan untuk menurunkan jumlah kematian dengan memberikan perawatan efektif (stabilisasi) terhadap korban secepat mungkin. Upaya stabilisasi korban mencakup intubasi, trakeostomi, pemasangan drain thoraks, pemasangan ventilator, penatalaksanaan syok secara medikamentosa, analgesia, pemberian infus, fasiotomi, imobilisasi fraktur, pembalutan luka, pencucian luka bakar. Fungsi pos medis lanjutan ini dapat disingkat menjadi"Three "T"rule" (Tag, Treat, Transfer) atau hukum tiga (label, rawat, evakuasi). Lokasi pendirian pos medis lanjutan sebaiknya yang cukup dekat untuk ditempuh dengan berjalan kaki dari lokasi bencana (50-100 meter) dan daerah tersebut harus:

1. Termasuk daerah yang aman

2. Memiliki akses langsung ke jalan raya tempat evakuasi dilakukan

3. Berada di dekat dengan pos komando

4. Berada dalam jangkauan komunikasi radio.

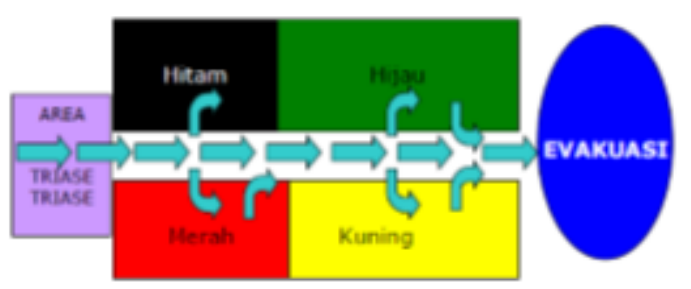

Gambar 1. Pos pelayanan medis latihan dasar 


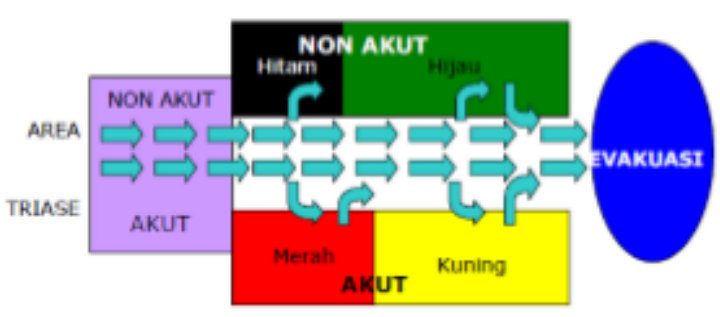

Gambar 2. Pos pelayanan medis lanjutan standar

Teknik evakuasi korban cedera kepala menggunakan teknik Log Roll agar badan korban setiap saat dijaga pada posisi lurus sejajar (seperti sebuah batang kayu). Teknik ini membutuhkan 2-5 tenaga medis. Untuk korban yang mengalami cedera servikal, harus mempertahankan kepala dan leher korban tetap sejajar (Suarningsih, 2017).

\section{Triase}

Triase dilakukan untuk mengidentifikasi secara cepat korban yang mebutuhkan stabilisasi segera (perawatan di lapangan) mengidentifikasi korban yang hanya dapat diselamatkan dengan pembedahan darurat (life-saving surgery). ${ }^{7}$

Terapi didasarkan pada kebutuhan ABCDE, dengan mengunakan metode START (Simple treatment and Rapid Treatment). Dalam aktivitasnya, digunakan kartu merah, hijau dan hitam sebagai kode identifikasi korban, seperti berikut:

1. Merah Sebagai penanda korban yang membutuhkan stabilisasi segera dan korban yang mengalami: Syok oleh berbagai kausa, gangguan pernapasan, trauma kepala dengan pupil anisokor, perdarahan eksternal massif. Pemberian perawatan lapangan intensif ditujukan bagi korban yang mempunyai kemungkinan hidup lebih besar, sehingga setelah perawatan dilapangan ini penderita lebih dapat mentoleransi proses pemindahan ke Rumah Sakit, dan lebih siap untuk menerima perawatan yang lebih invasif.Triase ini korban dapat dikategorisasikan kembali dari status "merah" menjadi "kuning" (misalnya korban dengan tension pneumothorax yang telah dipasang drain thoraks (WSD). ${ }^{7}$

2. Kuning Sebagai penanda korbanyang memerlukan pengawasan ketat, tetapi perawatan dapat ditunda sementara. Termasuk dalam kategori ini: Korban dengan risiko syok (korban dengan gangguan jantung, trauma abdomen), frakturmultipel, fraktur femur/pelvis, lukabakar luas, gangguan kesadaran/trauma kepala. Pada korban dengan status yang tidak jelas harus diberikan infus, pengawasan ketat terhadap kemungkinan timbulnya komplikasi, dan diberikan perawatan sesegera mungkin. ${ }^{7}$

3. Hijau Sebagai penanda kelompok korban yang tidak memerlukan pengobatan atau pemberian pengobatan dapat ditunda, mencakup korban yang mengalam fraktur minor, lukaminor, luka bakar minor. Korban dalam kategori ini, setelah pembalutan luka dan atau pemasangan bidai dapat dipindahkan pada akhir operasi lapangan. Korban dengan prognosis infaust, jika masih hidup pada akhir operasi lapangan, juga akan dipindahkan ke fasilitas kesehatan. ${ }^{7}$

4. Hitam Sebagai penanda korban yang telah meninggal dunia.

Triase lapangan dilakukan pada tiga kondisi, yaitu triase di tempat (triase satu), triase medik (triase dua), triase evakuasi (triase tiga). Triase di tempat dilakukan di "tempat korban ditemukan" atau pada tempat penampungan yang dilakukan oleh tim pertolongan pertama atau tenaga medis gawat darurat. Triase di tempat mencakup pemeriksaan, klasifikasi, pemberian tanda dan pemindahan korban ke pos media lanjutan. Triase medik dilakukan saat korban memasuki pos medis lanjutan oleh tenaga medis yang berpengalaman (sebaiknya dipilih dari dokter yang bekerja di Unit Gawat Darurat, kemudian ahli anestesi dan terakhir oleh dokter bedah). 
Tujuan triase medik adalah menentukan tingkat perawatan yang dibutuhkan oleh korban. Triase evakuasi ditujukan pada korban yang dapat dipindahkan ke Rumah Sakit yang telah siap menerima korban bencana massal. Jika pos medis lanjutan dapat berfungsi efektif, jumlah korban dalam status "merah" akan berkurang, dan akan diperlukan pengelompokan korban kembali sebelum evakuasi dilaksanakan. Tenaga medis di pos medis lanjutan dengan berkonsultasi dengan Pos Komando dan Rumah Sakit tujuan berdasarkan kondisi korban akan membuat keputusan korban mana yang harus dipindahkan terlebih dahulu, Rumah Sakit tujuan, jenis kendaraan dan pengawalan yang akan dipergunakan. ${ }^{7}$

Menurut Oman yang dikutip dalam jurnal gustia (2018) bahwa penilaian triase terdiri dari Primary survey dan Secondary survey prioritas dan monitoring korban. Primary survey (ABC) untuk menghasilkan prioritas I dan seterusnya. Secondary survey pemeriksaan menyeluruh (Head to Toe) untuk menghasilkan prioritas I, II, III, dan selanjutnya. Monitoring korban akan ada kemungkinan terjadi perubahan-perubahan pada $(\mathrm{A}, \mathrm{B}, \mathrm{C})$ derajat kesadaran dan tanda vital lainnya.

\section{Primary survey}

1. Airway dengan kontrol servikal Penilaian dengan mengenal patensi airway (inspeksi, auskultasi, palpasi). Penilaian secara cepat dan tepat akan adanya obstruksi. Pengelolaan airway dan melakukan chin lift dan atau jaw thrust dengan kontrol servikal in-line immobilisasi.

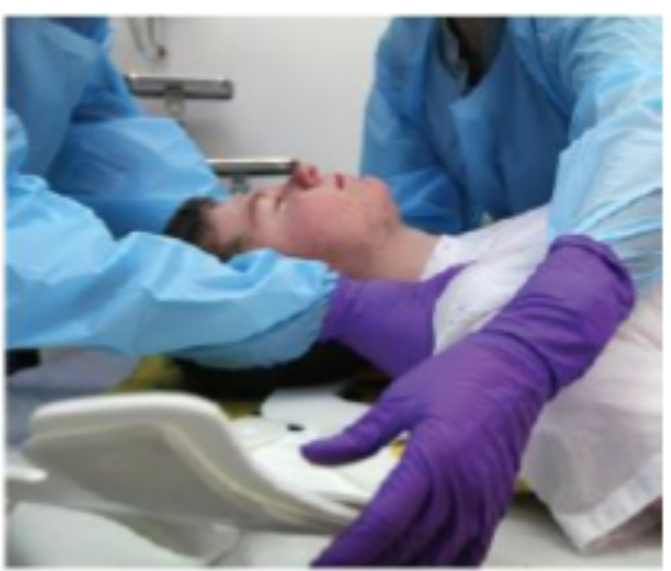

Gambar 3. In-line Immobilisasi

Bersihkan airway dari benda asing bila perlu suctioning dengan alat yang rigid. Dan pasang pipa nasofaringeal atau orofaringeal dan airway definitif sesuai indikasi. Fiksasi leher dan anggaplah bahwa terdapat kemungkinan fraktur servikal pada setiap penderita multi trauma, terlebih bila ada gangguan kesadaran atau perlukaan diatas klavikula. Kemudian evaluasi. ${ }^{12}$

2. Breathing dan Ventilasi-Oksigenasi Lakukan penilaian dan buka leher dan dada penderita, dengan tetap memperhatikan kontrol servikal in-line immobilisasi. Mentukan laju dan dalamnya pernapasan.

3. Circulation dengan kontrol perdarahan Penilaian dengan mengetahui perdarahan eksternal yang fatal dan sumber. Pengelolaan, penekanan langsung pada sumber perdarahan eksternal. Dan mengenali perdarahan internal, kebutuhan untuk intervensi bedah serta konsultasi pada ahli bedah. Pasang kateter IV 2 jalur ukuran besar sekaligus mengambil sampel darah untuk pemeriksaan rutin, kimia darah, tes kehamilan (pada wanita usia subur), golongan darah dan cross-match serta Analisis Das Darah (BGA). Beri cairan kristaloid yang sudah dihangatkan dengan tetesan cepat. Pasang PSAG/bidai pneumatik untuk kontrol perdarahan pada pasien-pasien fraktur pelvis yang mengancam nyawa. Cegah hipotermia dan evaluasi 
4. Disability Pertama tentukan tingkat kesadaran memakai skor GCS/PTS. Nilai pupil berupa besarnya, isokor atau tidak, reflek cahaya dan awasi tandatanda lateralisasi. Evaluasi dan Reevaluasi airway, oksigenasi, ventilasi dan circulation

5. Exposure/Environment Buka pakaian penderita cegah hipotermia, beri selimut hangat dan tempatkan pada ruangan yang cukup hangat. ${ }^{12}$

\section{Resusitasi}

Resusitasi sebagai upaya pertolongan pada korban dengan memberikan bantuan hidup dasar untuk menyelaatkan jiwa korban. Pertama dengan re-evaluasi ABCDE. Dosis awal pemberian cairan kristaloid adalah $10002000 \mathrm{ml}$ pada dewasa dan $20 \mathrm{~mL} / \mathrm{kg}$ pada anak dengan tetesan cepat. Lakukan evaluasi resusitasi cairan. Pemberian cairan selanjutnya berdasarkan respon terhadap pemberian cairan awal. Menilai keadaan respon cepat, respon sementara, dan tanpa respon. ${ }^{12}$

Resusitasi jantung paru harus dilakukan secara tepat guna menghindari komplikasi yang mungkin terjadi setelah cedera pada tulang iga, fraktur sternum atas, dan klavikula, ruptur diafragma, hepar, lien dan distensi lambung serta infeksi. ${ }^{14}$

\section{Transfer ke pusat rujukan yang lebih baik}

Pasien dirujuk apabila rumah sakit tidak mampu menangani pasien karena keterbatasan SDM (Sumber Daya Manusia) maupun fasilitas serta keadaan pasien yang masih memungkinkan untuk dirujuk. Tentukan indikasi rujukan, prosedur rujukan dan kebutuhan penderita selama perjalanan serta komunikasikan dengan dokter pada pusat rujukan yang dituju. Transfer dilakukan dengan memperhatikan prinsip ABCDE dan menjaga stabilisasi agar tidak terjadi cedera sekunder. ${ }^{12}$
Peralatan yang diperlukan untuk stabilisasi transportasi dalam evakuasi.

1. Cervical collar/penyangga leher Digunakan untuk melakukan imobilisasi tulang leher untuk mencegah gerkan leher yang berlebihan.

2. Short spine/ penyangga tulang belakang pendek Untuk memfiksasi bagian tubuh tertentu seperti kepala, dada dan perut

3. Long spine board/ penyangga tulang belakang panjang. Untuk membawa korban dengan posisi netral sehingga menghindari kerusakan tulang belakang

4. Wheeled stretcher Tandu yang ada rodanya, biasanya untuk membawa korban dari lokasi kejadian ke rumah sakit.

5. Scoop stretcher Untuk kasus-kasus cedera tulang kecuali cedera tulang belakang.

\section{Arus Pemindahan}

Korban yang telah diberi tanda dengan kartu berwarna merah, kuning, hijau atau hitam sesuai dengan kondisi mereka, dilakukan registrasi secara bersamaan dan korban langsung dipindahkan ke tempat perawatan yang sesuai dengan kartu yang diberikan hingga keadaannya stabil. Setelah stabil korban akan dipindahkan ke tempat evakuasi dimana registrasi mereka akan dilengkapi sebelum dipindahkanke fasilitas lain. ${ }^{15}$

Apabila terpaksa memindahkan korban, angkat korban secara perlahan-lahan tanpa merenggutnya. Pemindahan dapat menggunakan tandu dengan bagian tengah keras untuk membawa korban yang dicurigai menderita cedera di kepala atau tulang belakang. ${ }^{16}$

\section{KESIMPULAN}

Cedera kepala memiliki morbiditas dan mortalitas tinggi di dunia. Oleh karena itu, berdasarkan hasil diskusi dari tinjauan literatur ini, teknik evakuasi cedera kepala 
pada korban bencana harus dilakukan dengan cepat dan tepat. Evakuasi dilakukan dengan memindahkan korban ke tempat yang lebih aman, yaitu dari lokasi kejadian ke pos lanjutan dan dari pos lanjutan ke rumah sakit. Pemindahan tersebut merupakan prioritas penting setelah melakukan tindakan-tindakan pencegahan kematian seperti pemeriksaan tanda-tanda vital dan pada kondisi yang lebih lanjut dengan resusitasi.

Alur evakusi korban cedera kepala dimulai dari persiapan di area bencana dengan prinsip DRCAB, dan pemindahan korban menggunakan tandu keras serta menjaga stabilisasi cervical. Penanganannya berdasarkan identifikasi triase dengan memperhatikan ABCDE menggunakan metode START.

Pada evakuasi korban dengan cedera kepala tetap memperhatikan dan menjaga patensi airway, serta memonitor breathing dan sirkulasi. Dengan demikian cedera otak sekunder dapat dicegah selama proses evakuasi.

\section{REFERENSI}

1. Habibie T, Bidjuni H, \& Malara RT. "Hubungan Cedera Kepala dengan Disorientasi pada Pasien Kecelakaan Lalu lintas di IGD RS Bayangkara Manado". e-Journal Keperawatan, 2017; 5(1).

2. Rawis M, Lalenoh D, \& Kumaat, L. "Profil Pasien Cedera Kepala Sedang dan Berat yang Dirawat di ICU dan HCU”. Jurnal eclinic, 2016; 4(2).

3. Kementrian Kesehatan RI. Riset Kesehatan Dasar. 2013; Jakarta.

4. Gustia M, \& Manurung M. "Hubungan Ketepatan Penilaian Triase dengan Tingkat Keberhasilan Penanganan Pasien Cedera Kepala di IGD RSU HKBP Balige Kabupaten Toba Samosir". Jurnal Jumantik, 2018; 3(2).

5. Awaloei, AC, Mallo N, \& Tomuka D. "Gambaran Cedera Kepala yang Menyebabkan Kematian dibagian
Forensik dan Medikolegal RSUP Prof. Dr. R. D. Kandou”. Jurnal e-clinic, Periode Juni 2015 - Juli 2016; 4(2).

6. Basuki WS, Suryono B., \& Saleh SC. "Penatalaksanaan Perioperatif Cedera Kepala Traumatik Berat dengan Tanda Cushing”. Jurnal Neuroanastesi Indonesia, 2015; 4(1): 34-42.

7. Kementerian Kesehatan RI. Pedoman Teknis Penanggulangan Krisis Kesehatan Akibat Bencana. Jakarta. 2011

8. Suarningsih NKA. Pelaksanaan Teknik Memindahkan Pasien Trauma. Fakultas Kedokteran, Universitas Udayana. 2017

9. Martono S, Ratnawati R, \& Setyoadi. "Penanganan Kesehatan pada Tanggap Darurat Bencana Erupsi Gunung Merapi". Medica Hospitalia, 2014;2(3): 197-204.

10. Kementrian Kesehatan RI. Pedoman Penanganan Evakuasi Medik. Jakarta, 2009

11. AmatyaB, dkk. "Minimun Technical Standards and Recomendations for Traumatic Brain Injury Rehabilitation Teams in SuddenOnset Disaster". The Journal of the International Society of Physical and Rehabilitation Medicine. 2019; 1(2).

12. Rotondo MF, dkk. Advanced Trauma Life Suport (ATLS) 9th edition. Chicago: American College of Surgeons; 2012.

13. Pusbankes 118.Penanggulangan Penderita Gawat Darurat (PPGD), Basic Trauma and Cardiac Support (BTCLS). Yogyakarta: Persi DIY. 2013.

14. Kurniati A. PPGD dan Tagana Bantuan Hidup Dasar (BHD), Penanganan Pendarahan dan Pemindahan Korban. Jakarta: Australian AID. 2015

15. Machmud R. "Peran Petugas Kesehatan dalam Penanggulangan Bencana Alam". Jurnal Kesehatan Masyarakat, 2009;3(1). 
16. Yayasan IDEP. Pertolongan Pertama Gawat Darurat.

17. Suwarjaya IP, dan Wargahadibrata AH..Manajemen Perioperatif Epidural Hemorrhage Akibat Cedera Otak Traumatik. Jurnal Neoroanastesia Indonesia, 2012; 1(1): 10-5. 